\title{
Human normal hepatocytes are susceptible to apoptosis signal mediated by both TRAIL-R1 and TRAIL-R2
}

\author{
E Mori ${ }^{1}$, M Thomas ${ }^{1}, K^{\prime}$ Motoki ${ }^{1}, K_{\text {Nakazawa }}{ }^{1}, \mathrm{~T}$ Tahara ${ }^{1}$, \\ K Tomizuka ${ }^{1}$, I Ishida ${ }^{1}$ and S Kataoka ${ }^{*, 1}$ \\ 1 Pharmaceutical Research Laboratories, Kirin Brewery Co. Ltd., 3 Miyahara, \\ Takasaki, Gunma 370-1295, Japan \\ * Correspondence: S Kataoka. Tel: + 81-27-346-9788; \\ Fax: + 81-27-346-1971; E-mail: s-kataoka@ kirin.co.jp
}

Received 05.9.03; revised 09.9.03; accepted 09.9.03; published online 24.10.03 Edited by Dr. H Ichijo

\begin{abstract}
Tumor necrosis factor-related apoptosis-inducing ligand (TRAIL) triggers apoptosis in tumor cells without toxicity to normal cells, but some recombinant versions of TRAIL caused hepatocyte death. We generated fully human monoclonal antibodies (mAbs) that bind specifically to TRAIL receptor 1 (TRAIL-R1) and TRAIL receptor 2 (TRAIL-R2), which mediate apoptosis signal when they ligate with TRAIL, to investigate the contribution of each receptor to induce tumor cell apoptosis and hepatocyte toxicity. All of mAbs to TRAILR1 and TRAIL-R2 induced cell death in several cancer cell lines susceptible to TRAIL but not in human umbilical vein endothelial cells in vitro. Both anti-TRAIL-R1 mAbs and antiTRAIL-R2 mAbs also caused cell death in hepatocytes. However, a subset of mAbs to TRAIL-R2, which was characterized by the TRAIL blocking activity, did not show strong hepatocyte toxicity. These results indicate that human normal hepatocytes are susceptible to both TRAIL-R1- and TRAIL-R2-mediated apoptosis signal.

Cell Death and Differentiation (2004) 11, 203-207. doi:10.1038/ sj.cdd. 4401331

Published online 24 October 2003
\end{abstract}

Keywords: TRAIL; TRAIL-R1; TRAIL-R2; human antibody; hepatocyte

Abbreviations: TRAIL, tumor necrosis factor-related apoptosisinducing ligand; $\mathrm{mAb}$, monoclonal antibody; TRAIL-R1, TRAIL receptor 1; TRAIL-R2, TRAIL receptor 2

\section{Introduction}

Tumor necrosis factor-related apoptosis-inducing ligand (TRAIL) $)^{1,2}$ induces apoptosis in a wide variety of human cancer cell lines, but not in most normal human cells. ${ }^{3,4}$ TRAIL exhibits antitumor activity in tumor xenograft models ${ }^{3,4}$ and when administered in vivo, TRAIL shows little toxicity to normal tissues in mice and in non-human primates. ${ }^{4,5}$ However, it was reported that normal human hepatocytes, astrocytes and other brain cells were killed by recombinant soluble human TRAIL in vitro, ${ }^{3,6,7}$ which raised concern about the safety of TRAIL in cancer therapy. Recently, it was demonstrated that the method of preparing recombinant soluble ligand might be important for assessing the results of experiments with TRAIL. ${ }^{8,9}$

The mechanisms of hepatocyte toxicity by TRAIL remain unclear because of the difficulty in detection of TRAIL receptor expression in normal hepatocytes. TRAIL activates two distinct receptors, TRAIL-R1 (DR4) $^{10}$ and TRAIL-R2 (DR5), ${ }^{11-15}$ both possess a death domain in their cytoplasmic tail that can engage the apoptotic machinery. Thus, it is presumed that TRAIL-R1 and TRAIL-R2 or both are involved in the hepatocyte toxicity. Multivalent antibodies directed to these cell surface receptors in the TNF receptor family often mimic the action of the ligand by inducing receptor aggregation and triggering signal transduction pathways. ${ }^{16-18}$ To discern between the signaling of these two death receptors for tumor apoptosis and hepatocyte toxicity, we generated fully human monoclonal antibodies (mAbs) specific to TRAIL-R1 and TRAIL-R2.

Our study shows that the mAbs to TRAIL-R1 and TRAIL-R2 induced apoptosis in several human cancer cells in vitro, and that hepatocyte toxicity was also induced via both TRAIL-R1 and TRAIL-R2. Furthermore, a subset of anti-TRAIL-R2 mAbs characterized by the TRAIL blocking activity was low toxic to hepatocytes, which suggests that these antibodies may provide an alternate approach to circumvent the problems of hepatocyte toxicity, and that this potent biological signaling system may be still utilized to treat human cancer.

\section{Results}

Generation of fully human mAbs to TRAIL-R1 and TRAIL-R2

KM mice contain the human chromosome fragment encoding the entire human immunoglobulin heavy-chain loci and the YAC-transgene containing the human immunoglobulin kappa light-chain gene and when immunized produce complete human antibodies. ${ }^{19}$ We generated fully human mAbs reactive with TRAIL-R1 or TRAIL-R2. All of these mAbs specifically bound to the ectodomain of TRAIL-R1 or TRAIL$\mathrm{R} 2$ transfected in L929 cells as detected by flow cytometric analysis (Figure $1 \mathrm{a}$ and $\mathrm{b}$ ). The selected human mAbs to TRAIL-R1 and TRAIL-R2 demonstrated relatively high affinities to their respective antigens as detected by plasmon resonance assay (Table 1).

\section{In vitro apoptotic activity of human mAbs to TRAIL-R1 and TRAIL-R2}

The human mAbs to TRAIL-R1 and TRAIL-R2 were potent inducers of death of Colo205 cells in vitro. In the presence of 
anti-human IgG, which oligomerizes mAbs, these mAbs demonstrated potent agonistic activities on Colo205 cells in a dose-dependent manner (Figure 2a), whereas mAbs alone showed little cytotoxic activity (data not shown). To determine whether the cell death induced by these mAbs upon crosslinking was apoptosis or not, we measured effector caspase activity in mAbs-treated cancer cell. In this cell line, DEVDase activation was detected within $2 \mathrm{~h}$ after the mAbs treatment (Figure 2b).

These mAbs induced cell death in other human tumor cell lines that are susceptible to TRAIL, such as Jurkat, MDA-MB231, U251, but not human umbilical vein endothelial cells (HUVECs) (Figure 3), which express TRAIL-R1 and TRAILR2 but resistant to TRAIL. ${ }^{20}$ Although the degree of death varied between these cell lines, the relative potency of each $\mathrm{mAb}$ remained the same. However, in U251 glioma cell line the mAbs did not induce death by the treatment with antihuman IgG (data not shown), but required a combination treatment with cis-diamminedichloroplatinum(II) (CDDP), a DNA-damaging agent that resulted in cell death (Figure 3). Recombinant human soluble TRAIL also required CDDP to induce cell death of U251. ${ }^{21}$ This observation demonstrates that TRAIL and mAbs to TRAIL receptors are similar in their cytotoxic activity on these carcinoma cell lines. The activation of caspase was also detected within $2 \mathrm{~h}$ after the mAbs treatment in these cancer cell lines (data not shown). The extent of caspase activation was different between cell lines; however, it was correlated with the cytotoxic activity induced by the mAbs. These results revealed that mAbs to TRAIL-R1 and TRAIL-R2 induced apoptosis of these carcinoma cells via caspase activation.
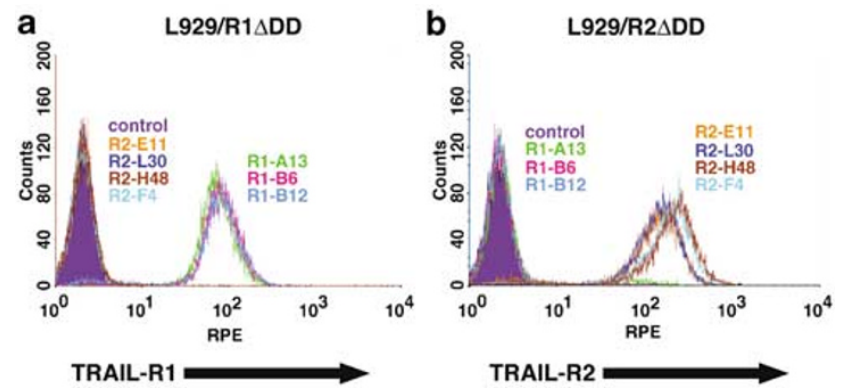

Figure 1 Binding activity of mAbs to TRAIL-R1 and TRAIL-R2. L929 cells transfected with death domain-deleted human TRAIL-R1 (L929/R1 $\triangle \mathrm{DD}$, a) and TRAIL-R2 (L929/R2 $\Delta D D$, b) were stained with mAbs to human TRAIL-R1 or TRAIL-R2, or control antibody. $X$-axis indicates the fluorescent signal intensity of RPE

Table 1 Physical characteristics of human anti-human TRAIL-Receptor mAb

\begin{tabular}{|c|c|c|c|c|c|c|}
\hline mAb & Specificity & $h$ and I chain isotype & TRAIL blocking & $k_{\mathrm{a}}^{\mathrm{a}}\left(10^{5} / \mathrm{M} / \mathrm{s}\right)$ & $k_{\mathrm{d}}^{\mathrm{b}}\left(10^{-4} / \mathrm{s}^{-1}\right)$ & $\mathrm{K}_{\mathrm{D}}^{\mathrm{c}}(\mathrm{nM})$ \\
\hline $\mathrm{R} 1-\mathrm{A} 13$ & TRAIL-R1 & $\operatorname{lgG} 4, \kappa$ & + & 1.1 & 4.6 & 4.2 \\
\hline $\mathrm{R} 1-\mathrm{B} 6$ & TRAIL-R1 & $\operatorname{lgG} 1, \kappa$ & + & 1.6 & 1.9 & 1.2 \\
\hline R1-B12 & TRAIL-R1 & $\lg G 1, \kappa$ & + & 1.6 & 7.8 & 4.9 \\
\hline R2-E11 & TRAIL-R2 & $\lg G 1, \kappa$ & + & 5.3 & 0.38 & 0.072 \\
\hline R2-L30 & TRAIL-R2 & $\lg \mathrm{G} 1, \kappa$ & + & 6.1 & 14 & 2.3 \\
\hline R2-H48 & TRAIL-R2 & $\lg \mathrm{G} 1, \kappa$ & - & 5.8 & 16 & 2.8 \\
\hline $\mathrm{R} 2-\mathrm{F} 4$ & TRAIL-R2 & $\lg G 1, \kappa$ & - & 5.6 & 7.1 & 1.3 \\
\hline
\end{tabular}

Values are the means of at least two measurements over a ligand concentration range of 2-134 nM (mAbs to TRAIL-R1) and 0.5-8.4 nM (mAbs to TRAIL-R2) ${ }^{\mathrm{a}} k_{\mathrm{a}}=$ association rate constant ${ }^{\mathrm{b}} k_{\mathrm{d}}=$ dissociation rate constant ${ }^{\mathrm{c}} K_{\mathrm{D}}=$ intrinsic dissociation constant (from $k_{\mathrm{d}} / k_{\mathrm{a}}$ )
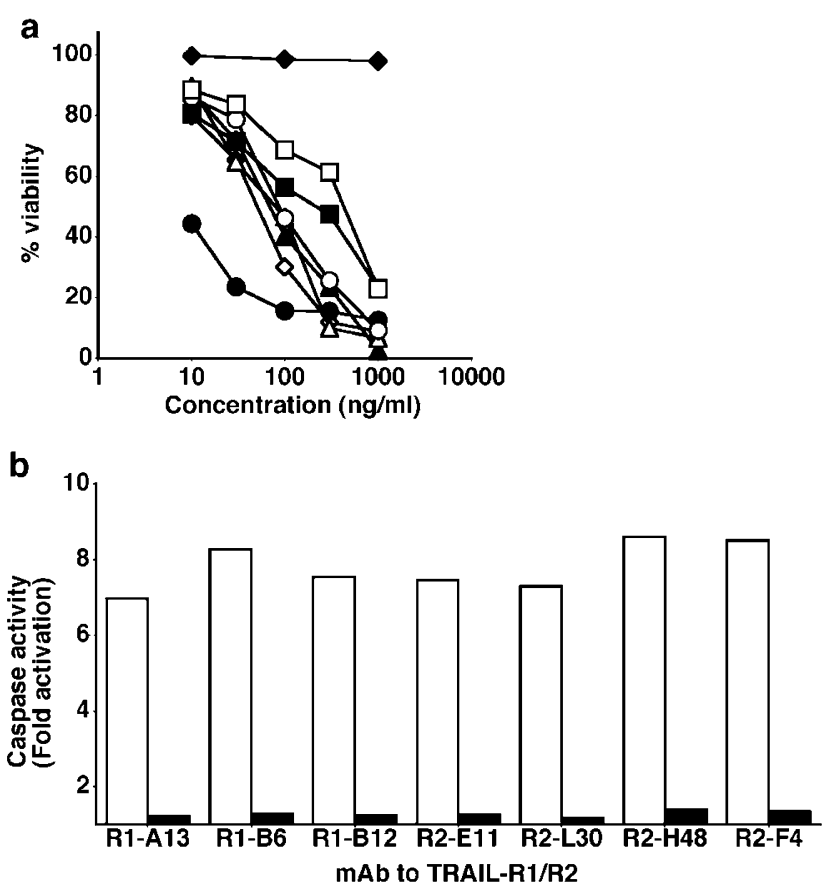

Figure 2 Apoptosis induced by mAbs via caspase activation. (a) Colo205 cells were incubated with the indicated concentrations of mAbs to TRAIL-R1, R1-A13

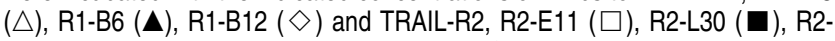
$\mathrm{H} 48(\bigcirc), \mathrm{R} 2-\mathrm{F} 4(\boldsymbol{O})$ and control antibody $(\bullet)$ in the presence of goat antihuman IgG. After cells were incubated for $48 \mathrm{~h}$ at $37^{\circ} \mathrm{C}$, the cell viability was determined. (b) Colo205 cells were incubated with mAbs to TRAIL-R1 and TRAIL-R2 at $1 \mu \mathrm{g} / \mathrm{ml}$ in the presence $(\square)$ or absence ( $\mathbf{C}$ ) of goat anti-human IgG. After cells were incubated for $2 \mathrm{~h}$ at $37^{\circ} \mathrm{C}$, the effector caspase activity was measured

\section{Hepatocyte toxicity of human mAbs to TRAIL-R1 and TRAIL-R2}

Hepatocyte toxicity of recombinant human soluble TRAIL may limit the usefulness of this reagent for treating tumors in vivo. Some preparations of TRAIL were reported to induce apoptosis in human normal hepatocytes in vitro. ${ }^{6} \mathrm{We}$ investigated whether the human mAbs to TRAIL-R1 and TRAIL-R2 were cytotoxic to human normal hepatocytes in the presence of anti-human IgG. All of the mAbs to TRAIL-R1 induced significant death and activated effector caspase in the hepatocyte cultures (Figure $4 \mathrm{a}$ and $\mathrm{d}$ ). Although antiTRAIL-R2 mAbs also induced cell death and caspase activation in hepatocytes, they were separated into two groups, one with and the other without strong hepatocyte toxicity (Figure 4b, c, e). A subset of mAbs to TRAIL-R2, 

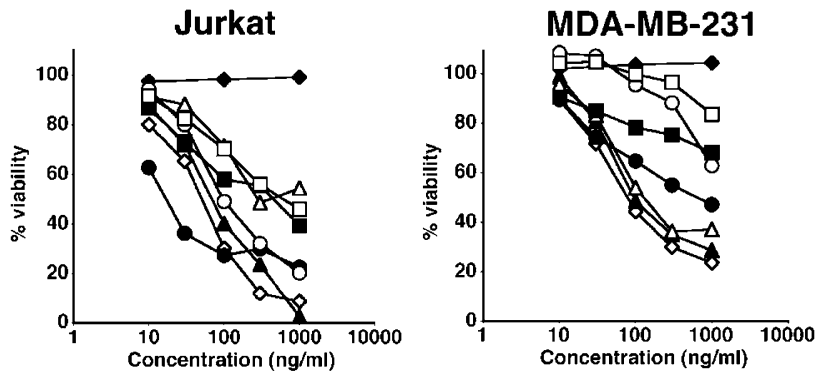

U251
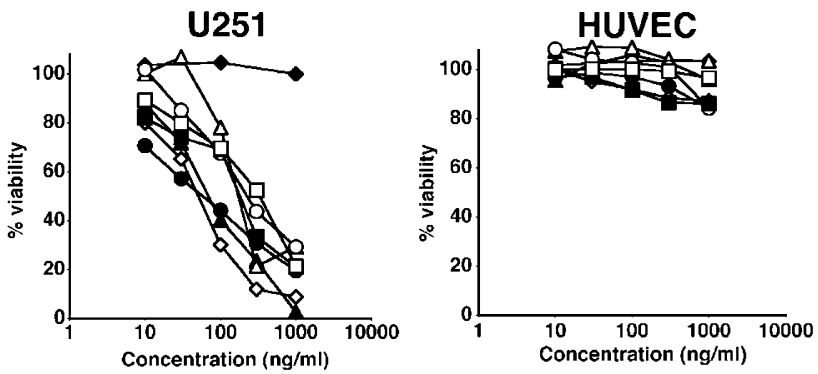

Figure 3 Effect of mAbs on viability of cancer cell lines and HUVECs. Jurkat, MDA-MB-231, U251 and HUVECs were incubated with the indicated concentrations of mAbs to TRAIL-R1, R1-A13 $(\triangle)$, R1-B6 $(\mathbf{\Delta}), \mathrm{R} 1-\mathrm{B} 12(\diamond)$ and TRAIL-R2, R2-E11 ( $\square$ ), R2-L30 ( $)$ ), R2-H48 ( $\bigcirc)$, R2-F4 (O) and control antibody $(\checkmark)$ in the presence of goat anti-human IgG. For U251 cells, $4 \mu \mathrm{g} / \mathrm{ml}$ CDDP was also added to the cultures. After cells were incubated for $48 \mathrm{~h}$ at $37^{\circ} \mathrm{C}$, the cell viability was determined

R2-E11 and R2-L30 competitively inhibited the binding of TRAIL to TRAIL-R2-Fc as detected by plasmon resonance assay (Table 1). By contrast, the other subset, R2-H48 and $\mathrm{R} 2-\mathrm{F} 4$, did not. These results indicated that normal human hepatocytes expressed both functional TRAIL-R1 and TRAIL$\mathrm{R} 2$, and hepatocytes were susceptible to both TRAIL-R1- and TRAIL-R2-madiated apoptosis signal.

\section{Discussion}

The reported toxicity to hepatocytes is largely dependent upon the version of recombinant TRAIL. ${ }^{8}$ One possibility causing the hepatocyte toxicity of the tagged versions of TRAIL is due to poor zinc ion coordination and formation of intersubunit disulfide bonds resulting in unstable heterogeneous oligomers. ${ }^{8}$ Recently, it was suggested that these nonoptimized ligands might cause high-order multimerization of TRAIL-R1 and TRAIL-R2, leading to apoptosis in the normal cells including hepatocytes. ${ }^{9}$ However, these data also indicated that functional TRAIL-R1 and/or TRAIL-R2 were expressed in hepatocytes. Ichikawa et al. ${ }^{18}$ demonstrated that TRA-8, an anti-TRAIL-R2 mAb of mouse origin, induced cell death in tumor cells but not in normal human hepatocytes because of a lack of binding of TRA-8 by hepatocytes. They suggested that there was little to no expression of TRAIL-R2 on human hepatocytes. However, our results presented here clearly indicate that all of the mAbs to TRAIL-R1 and a subset of TRAIL-R2 mAbs strongly caused apoptosis in human hepatocytes, demonstrating that both TRAIL-R1 and TRAIL-R2 are expressed and each receptor alone is sufficient to mediate death signals in human hepatocytes.
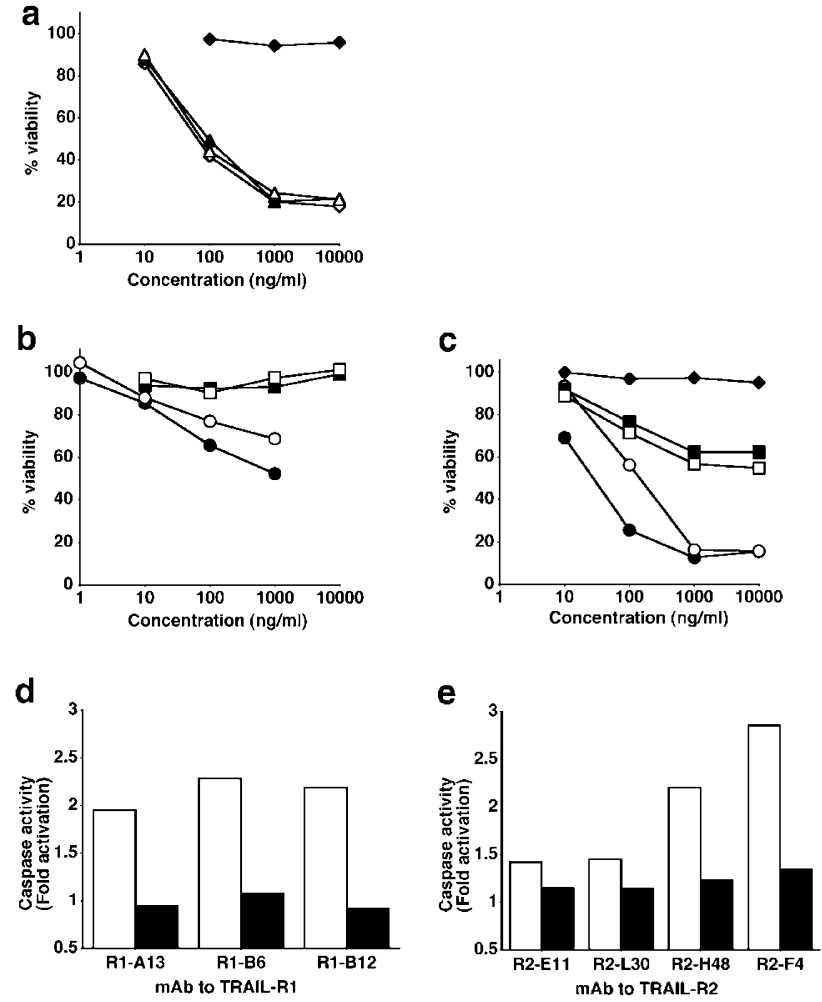

Figure 4 Hepatocyte toxicity of mAbs to TRAIL-R1 and TRAIL-R2 in vitro. Hepatocytes were treated with the indicated concentrations of mAbs to TRAILR1, R1-A13 $(\triangle)$, R1-B6 $(\mathbf{\Delta}), \mathrm{R} 1-\mathrm{B} 12(\diamond)$ and control antibody $(\diamond)$ in the presence of goat anti-human IgG for $24 \mathrm{~h}$ (a), or mAbs to TRAIL-R2, R2-E11 $(\square)$, R2-L30 (ם), R2-H48 (O), R2-F4 (@) and control antibody ( $)$ in the presence of goat anti-human IgG for $6 \mathrm{~h}$ (b) or $24 \mathrm{~h}$ (c). Human normal hepatocytes were incubated with mAbs to TRAIL-R1 (d) and TRAIL-R2 (e) at $1 \mu \mathrm{g} / \mathrm{ml}$ in the presence $(\square)$ or absence ( $\square$ ) of goat anti-human IgG. After cells were incubated for $2 \mathrm{~h}$ at $37^{\circ} \mathrm{C}$, the effector caspase activity was measured

The mechanism of action of the anti-TRAIL receptor $m A b$ is likely to be quite complex, involving properties of the antibody as well as features inherent to the tumor, that is, the stage of differentiation of the tumor, and its resistance to death signals at the time of introducing the antibody. A hint of this interdependence is observed with the U251 tumor cells, which required both CDDP and anti-TRAIL-receptor antibodies to induce death. The anti-TRAIL-R2 mAb (R2-E11) functions both as an antagonist and agonist, as an antagonist in its ability to block ligand binding (which may confer the low heptotoxicity), and as agonist through its antitumor activity. This dual behavior is a property inherent to the mechanism of activating the TNF receptors. Signaling is normally activated by receptor oligomerization caused by binding of the trivalent ligand. Antibody binding to the receptor sterically inhibits ligand access, while at the same time induces oligomerization of the receptor due to bivalent combining sites of the antibody molecule, which in turn initiates signal transduction pathways in ways similar to the ligand. In the case of TRAIL receptor and Fas, a supra-oligomerization is thought to be required for activation of death signaling. ${ }^{22}$ In agreement with the requirement of receptor oligomerization, our results indicate that anti-TRAIL receptor $\mathrm{mAbs}$ require a crosslinking agent to demonstrate agonistic activity in vitro. In contrast, in vivo, 
oligomerization of mAbs may be induced by an endogenous linker, such as the interaction of the Fc portion of mAbs with Fc receptor-bearing cells. The crosslinking of mAbs with $\mathrm{Fc}$ receptor on effector cells in vivo may differ from that with antihuman IgG in vitro. Therefore, the in vivo effects of endogenous linkers on mAbs to TRAIL receptors need to be further investigated.

Together, these results encourage the continued investigation of the TRAIL cytokine-receptor system for the treatment of human cancers. Fully human antibodies may avoid the potential problems arising from immunization of treated patients, and with the lack of hepatotoxicity, should prove valuable in this effort to develop effective immunotherapeutics for malignant disease.

\section{Materials and Methods}

\section{Cell lines}

Colo205 (colorectal adenocarcinoma), Jurkat (T-cell leukaemia) and MDAMB-231 (breast adenocarcinoma) were obtained from American Type Culture Collection (ATCC, Rockville, MD, USA). U251 (glioblastoma) was obtained from RIKEN CELL BANK (RCB, Tsukuba, Japan). Cell lines were maintained in RPMI1640 or DMEM supplemented $10 \%$ fetal bovine serum, streptomycin. HUVECs were purchased from Clonetics (Walkersville, MD, USA) and maintained in the medium recommended by the supplier.

\section{KM mice (KM Mouse ${ }^{\mathrm{TM}}$ )}

$\mathrm{KM}$ mice were generated by cross breeding double trans-chromosomic mice and transgenic mice. ${ }^{19} \mathrm{KM}$ mice possess the human chromosome fragments containing the entire human immunoglobulin heavy-chain loci and the YAC-transgene for $50 \%$ of the human immunoglobulin kappa lightchain loci. KM mice are engineered to neither express endogenous immunoglobulin heavy chain nor kappa light chain.

\section{Generation of fully human mAbs to TRAIL-R1 and TRAIL-R2}

KM mice were immunized by standard methods with L929 cells transfected with either death domain-deleted TRAIL-R1 (amino acids 1351) or TRAIL-R2 (amino acids 1-348) as the immunogen and fused with SP2/0 cells (ATCC, Rockville, MD, USA). Antibody-secreting hybridomas were initially screened by a plate-bound ELISA and secondarily by flow cytometry. Isotypes of mAbs were determined in an isotyping ELISA (The Binding Site, Birmingham, UK). Antibodies were purified from hybridoma culture supernatants with Protein A (Amersham Biosciences Corp., Piscataway, NJ, USA) by standard methods.

\section{Flow cytometry}

Cells $\left(1 \times 10^{6}\right.$ cells/sample) were washed with PBS containing $1 \%$ FBS and $0.1 \% \mathrm{NaN}_{3}$ and incubated with $1 \mu \mathrm{g} / \mathrm{ml}$ of human mAbs to TRAIL-R1 and TRAIL-R2 for $1 \mathrm{~h}$ on ice. Cells were washed and stained with Rphycoerythrin (RPE)-labeled rabbit polyclonal anti-human kappa light chains antibodies (DAKO, Glostrup, Denmark) on ice for $1 \mathrm{~h}$. After washing, cells were analyzed on FACScan flow cytometer (BD, Franklin Lakes, NJ, USA).

\section{Cytotoxicity assay}

Cancer cell lines and HUVECs were seeded in 96-well plates $\left(1 \times 10^{4}\right.$ per well) and incubated with the indicated concentrations of human mAbs to TRAIL-R1 and TRAIL-R2 with or without goat anti-human IgG $(10 \mu \mathrm{g} / \mathrm{ml})$ for $48 \mathrm{~h}$. Cell viability was determined by CellTiter $96^{\circledR} A Q_{\text {ueous }}$ NonRadioactive Cell Proliferation Assay (Promega, Madison, WI, USA).

\section{Human hepatocyte cultures}

Human normal hepatocytes were purchased from Tissue Transformation Technologies (Edison, NJ, USA) and In Vitro Technologies (Baltimore, MD, USA). Hepatocytes were dispensed into a type-I collagen-coated plate (BD, Franklin Lakes, NJ, USA) in CM5300 medium (CEDRA, Austin, TX, USA). After overnight incubation at $37^{\circ} \mathrm{C}$, the plate was washed with PBS to remove unattached cells. Hepatocytes were incubated in CM5300 containing the indicated concentrations of human mAbs to TRAIL-R1 and TRAIL-R2 with or without goat anti-human IgG $(10 \mu \mathrm{g} / \mathrm{ml})$ for 6 or $24 \mathrm{~h}$. Hepatocyte viability was determined by CytoTox $96^{\mathbb{R}}$ Non-Radioactive Cytotoxic Assay (Promega, Madison, WI, USA).

\section{Caspase activity}

Cancer cell lines and human normal hepatocytes were seeded and incubated with human mAbs to TRAIL-R1 and TRAIL-R2 $(1 \mu \mathrm{g} / \mathrm{ml})$ with or without goat anti-human IgG $(10 \mu \mathrm{g} / \mathrm{ml})$ for $2 \mathrm{~h}$. Caspase activity was measured by Apo-ONE ${ }^{\mathrm{TM}}$ Homogeneous Caspase-3/7 Assay (Promega, Madison, WI, USA) and potency of caspase activation was calculated compared to nontreated cells.

\section{Acknowledgements}

We thank Dr. Carl F Ware for thoughtful discussion, his critical comments and reviewing the manuscript, and Dr. Tadashi Sudo for careful reading of the manuscript. We also acknowledge Hikaru Hashida and Chiharu Tanaka for their technical assistance.

\section{References}

1. Wiley SR, Schooley K, Smolak PJ, Din WS, Huang CP, Nicholl JK, Sutherland GR, Smith TD, Rauch C and Smith CA (1995) Identification and characterization of a new member of the TNF family that induces apoptosis. Immunity 3: 673-682

2. Pitti RM, Marsters SA, Ruppert S, Donahue CJ, Moore A and Ashkenazi A (1996) Induction of apoptosis by Apo-2 ligand, a new member of the tumor necrosis factor cytokine family. J. Biol. Chem. 271: 12687-12690

3. Walczak H, Miller RE, Ariail K, Gliniak B, Griffith TS, Kubin M, Chin W, Jones J, Woodward A, Le T, Smith C, Smolak P, Goodwin RG, Rauch CT, Schuh JC and Lynch DH (1999) Tumoricidal activity of tumor necrosis factor-related apoptosis-inducing ligand in vivo. Nat. Med. 5: 157-163

4. Ashkenazi A, Pai RC, Fong S, Leung S, Lawrence DA, Marsters SA, Blackie C, Chang L, McMurtrey AE, Hebert A, DeForge L, Koumenis IL, Lewis D, Harris L, Bussiere J, Koeppen H, Shahrokh Z and Schwall RH (1999) Safety and antitumor activity of recombinant soluble Apo2 ligand. J. Clin. Invest. 104: 155162

5. Kelley SK, Harris LA, Xie D, Deforge L, Totpal K, Bussiere J and Fox JA (2001) Preclinical studies to predict the disposition of Apo2L/tumor necrosis factorrelated apoptosis-inducing ligand in humans: characterization of in vivo efficacy, pharmacokinetics, and safety. J. Pharmacol. Exp. Ther. 299: 31-38

6. Jo M, Kim TH, Seol DW, Esplen JE, Dorko K, Billiar TR and Strom SC (2000) Apoptosis induced in normal human hepatocytes by tumor necrosis factorrelated apoptosis-inducing ligand. Nat. Med. 6: 564-567 
7. Nitsch R, Bechmann I, Deisz RA, Haas D, Lehmann TN, Wendling U and Zipp $F(2000)$ Human brain-cell death induced by tumour-necrosis-factor-related apoptosis-inducing ligand (TRAIL). Lancet 356: 827-828

8. Lawrence D, Shahrokh Z, Marsters S, Achilles K, Shih D, Mounho B, Hillan K, Totpal K, DeForge L, Schow P, Hooley J, Sherwood S, Pai R, Leung S, Khan L, Gliniak B, Bussiere J, Smith CA, Strom SS, Kelley S, Fox JA, Thomas D and Ashkenazi A (2001) Differential hepatocyte toxicity of recombinant Apo2L/ TRAIL versions. Nat. Med. 7: 383-385

9. LeBlanc HN and Ashkenazi A (2003) Apo2L/TRAIL and its death and decoy receptors. Cell Death Differ. 10: 66-75

10. Pan G, O'Rourke K, Chinnaiyan AM, Gentz R, Ebner R, Ni J and Dixit VM (1997) The receptor for the cytotoxic ligand TRAIL. Science 276: $111-113$

11. Pan G, Ni J, Wei YF, Yu G, Gentz R and Dixit VM (1997) An antagonist decoy receptor and a death domain-containing receptor for TRAIL. Science 277: 815-818

12. Sheridan JP, Marsters SA, Pitti RM, Gurney A, Skubatch M, Baldwin D, Ramakrishnan L, Gray CL, Baker K, Wood WI, Goddard AD, Godowski P and Ashkenazi A (1997) Control of TRAIL-induced apoptosis by a family of signaling and decoy receptors. Science 277: 818-821

13. Walczak H, Degli-Esposti MA, Johnson RS, Smolak PJ, Waugh JY, Boiani N, Timour MS, Gerhart MJ, Schooley KA, Smith CA, Goodwin RG and Rauch CH (1997) TRAIL-R2: a novel apoptosis-mediating receptor for TRAIL. EMBO J. 16: $5386-5397$

14. Chaudhary PM, Eby M, Jasmin A, Bookwalter A, Murray J and Hood L (1997) Death receptor 5 , a new member of the TNFR family, and DR4 induce FADDdependent apoptosis and activate the NF-kappaB pathway. Immunity 7 : $821-830$
15. Screaton GR, Mongkolsapaya J, Xu XN, Cowper AE, McMichael AJ and Bell J (1997) TRICK2, a new alternatively spliced receptor that transduces the cytotoxic signal from TRAIL. Curr. Biol. 7: 693-696

16. Griffith TS, Rauch CT, Smolak PJ, Waugh JY, Boiani N, Lynch DH, Smith CA, Goodwin RG and Kubin MZ (1999) Functional analysis of TRAIL receptors using monoclonal antibodies. J. Immunol. 162: 2597-2605

17. Chuntharapai A, Dodge K, Grimmer K, Schroeder K, Marsters SA, Koeppen H, Ashkenazi A and Kim KJ (2001) Isotype-dependent inhibition of tumor growth in vivo by monoclonal antibodies to death receptor 4. J. Immunol. 166: 4891-4898

18. Ichikawa K, Liu W, Zhao L, Wang Z, Liu D, Ohtsuka T, Zhang H, Mountz JD, Koopman WJ, Kimberly RP and Zhou T (2001) Tumoricidal activity of a novel anti-human DR5 monoclonal antibody without hepatocyte cytotoxicity. Nat. Med. 7: 954-960

19. Ishida I, Tomizuka K, Yoshida H, Tahara T, Takahashi N, Ohguma A, Tanaka S, Umehashi M, Maeda H, Nozaki C, Halk E and Lonberg N (2002) Production of human monoclonal and polyclonal antibodies in TransChromo (TC) animals. Cloning Stem Cells 4: 91-102

20. Zhang XD, Nguyen T, Thomas WD, Sanders JE and Hersey $P(2000)$ Mechanisms of resistance of normal cells to TRAIL induced apoptosis vary between different cell types. FEBS Lett. 482: 193-199

21. Nagane M, Pan G, Weddle JJ, Dixit VM, Cavenee WK and Huang HJ (2000) Increased death receptor 5 expression by chemotherapeutic agents in human gliomas causes synergistic cytotoxicity with tumor necrosis factor-related apoptosis-inducing ligand in vitro and in vivo. Cancer Res. 60: 847-853

22. Schneider P, Holler N, Bodmer JL, Hahne M, Frei K, Fontana A and Tschopp J (1998) Conversion of membrane-bound Fas (CD95) ligand to its soluble form is associated with downregulation of its proapoptotic activity and loss of liver toxicity. J. Exp. Med. 187: 1205-1213 